\title{
Teaching Evidence-Based Subject Didactics in Primary Teacher Education
}

\author{
Esta Sikkal ${ }^{a}$, Krista Uibu ${ }^{*}$, , Irja Vaas ${ }^{c}$, Tiia Krass ${ }^{d}$
}

$\begin{array}{ll}\text { Received } & : \text { 14 December } 2020 \\ \text { Revised } & : \text { 27 May } 2021 \\ \text { Accepted } & : \text { 15 June } 2021 \\ \text { DOI } & : \text { 10.26822/iejee.2021.218 }\end{array}$

"Esta Sikkal, Institute of Education, University of Tartu,

Tartu, Estonia

E-mail: esta.sikkal@ut.ee

ORCID: https://orcid.org/0000-0002-8278-2557

"bCorresponding Author: Krista Uibu,

Institute of Education, University of Tartu, Estonia.

E-mail: krista.uibu@ut.ee

ORCID: https://orcid.org/0000-0001-6740-1771

Irja Vaas, Institute of Education, University of Tartu, Tartu, Estonia

E-mail: irja.vaas@ut.ee

ORCID: https://orcid.org/0000-0001-5559-8204

'Tiia Krass, Institute of Education, University of Tartu, Tartu, Estonia

E-mail: tiia.krass@ut.ee

ORCID: https://orcid.org/0000-0002-1247-4305

\begin{abstract}
For contemporary teaching, teachers need good knowledge of pedagogy, content, subject methodology and assessment. Although subject didactics have become an independent research area with interdisciplinary dimensions, few studies focus on the teaching of subject didactios. With the aim of developing a theoretical model for the systematic treatment of subject didactics, a scoping literature review was carried out to analyse the scientific literature. Twenty-five articles were chosen from different databases in the field of study. Data analyses revealed three domains of subject didactics: content knowledge, pedagogical content knowledge and knowledge of subjectspecific assessment. These domains included various components which were used for developing a theoretical model for teaching subject didactics within the framework of primary teacher education. The results indicated how to organise university courses on subject didactics for primary teachers. First, teachers' content knowledge and pedagogical knowledge should be treated in an integrated way. Second, integrating pedagogical knowledge with subject didactics enables teacher education to be shaped so that students understand the teaching profession at an early stage. Third, studying subject didactics on both a theoretical and empirical level is the driving force for developing syllabi in primary teacher education.
\end{abstract}

\section{Keywords:}

Primary Teacher Education, Subject Didactics Model, Evidence-Based Teaching, Scoping Literature Review

\section{Introduction}

In order to teach successfully, teachers need a thorough knowledge of different areas; they need to know the content and structure of the subject they teach, as well as subject didactics and pedagogy. Although the core issues of didactics as a branch of pedagogy have been discussed in Europe as early as the 17th century, the more systematic development of didactics began in Germany during the 1950s (Klafki, 2000). It was through assessing the teaching process that questions emerged about how to treat and 
define the dimensions between general didactics, i.e. the general objectives, forms and means of education, and subject didactics, i.e. the theoretical and practical foundations of education, teaching and pedagogy (Kansanen \& Meri, 1999; Klafki, 2000). This approach is made particularly complex by the fact that the definitions of 'didactics' and 'methodology' are not clearly distinguished in conventional use, and their substantive semantic field remains somewhat blurred. Furthermore, it is not always easy to differentiate between the content of concepts of didactics and methodology.

There is consensus, however, that teacher's pedagogical content knowledge is a critical part of successful teaching, which includes subjective and individual decisions by the teacher and the understanding of how to present the subject taught in a manner that is appropriate and comprehensible for pupils (see Deng, 2018; Küçükaydın \& Sağır, 2016; Ozmantar \& Akkoç, 2017). The subjective nature of pedagogical content knowledge might be one of the reasons (Ozmantar \& Akkoç, 2017) why teacher training lacks a holistic concept of teaching and developing different subject didactics (Doyle et al., 2019; Vollmer, 2014). The second reason may be that the simplified approach to pedagogical content knowledge only includes knowledge of teaching and how to use instructional methods, while their association with theoretical foundations remains superficial (Meijer, 2013). This is why it is considered important to focus on specific areas and components during empirical studies of subject didactics and to rely on proven theoretical approaches and models when planning subject didactics courses as a part of primary teacher education (Ozmantar \& Akkoç, 2017; Park \& Oliver, 2008).

There appears to be a lack of consensualunderstanding about what areas, components and connections to highlight in relation to teachers' pedagogic content knowledge (Gess-Newsome, 2017; Park \& Oliver, 2008). Therefore, some topics and components are presented more frequently than others in models of subject didactics. There are two topics that are considered very important in innovative teaching, originating from Lee Shulman's studies (Shulman, 1986, 1987): the need to understand learners and their way of learning and teaching strategies and their application in the process of teaching.

The development of subject didactics as an independent field of research has been surprisingly dynamic in recent decades, both at the theoretical and practical level (Heizmann, 2013). Although different schools address the concepts of subject didactics somewhat differently, it has become an area of interdisciplinary dimension in which different research methods are used and are systematically developed. For example, in addition to quantitative research methods, case studies (Küçükaydın \& Sağır, 2016) or documented lesson analysis (Bonnet, 2009) are also used, focusing on the design of knowledge, the scientific description of content and the analysis of practical comprehension and action. However, in Estonia, where diametrically opposed paradigms and values are evident in the education system, there is no historical tradition of studying the teaching of subject didactics at universities (Studies in Social and Educational Sciences, 2014). This study examines the areas and components of primary school teachers' pedagogical content knowledge and relations between them that belong in the model of contemporary subject didactics. Using the methodology of a scoping literature review, the scientific literature on subject didactics published within the last decade in English and German is analysed, and a theoretical model for the systematic teaching of subject didactics within the framework of teacher training is being developed.

\section{Classification of Didactics}

Didactics are classified in different ways. The most elementary option is to divide didactics into general didactics and subject didactics. General didactics can be described as a set of teaching patterns that are independent from the specific content of subjects, levels of education and characteristics (Unt, 2013). In contrast, subject didactics include a set of patterns required to teach one subject or group of subjects. This includes the planning, conducting and analysing of teaching, which are complemented by the patterns of general didactics (Unt, 2013). A second option for classifying didactics is to distinguish between theoretical and applied didactics or, according to Vollmer (2014), into normative and practical subject didactics. This approach is based on the belief that applied didactics that have practical content must proceed from theoretical models and rationales and that all practical actions must rely on theoretical didactics in a way that creates synergy between them (Kansanen \& Meri, 1999; Vollmer, 2014). Applied didactics with practical content are used as a mediator (e.g. teaching is carried out at school in a specific situation) and are often a driving force for didactical innovation (Niermann, 2017; Vollmer 2014).

Based on such a hierarchical structure of didactics, Shulman (1987) identified the knowledge necessary for teachers' work and proposed a teacher knowledge model that includes three wider areas: 1) knowledge of the subject, i.e. content knowledge, 2) pedagogical knowledge, and 3) pedagogical content knowledge that unites pedagogy and subject knowledge. The main emphasis in this division is subject didactics, 
or how, using pedagogical knowledge, to teach a subject or a certain topic as effectively as possible.

Pedagogical content knowledge of teachers can be considered a key element in their professional development (Park \& Oliver, 2008; Richardson et al., 2018) as it differentiates them from experts in specific fields (Stender et al., 2017). Bohlmann (2016) describes pedagogical content knowledge as a fusion - an amalgam - of content knowledge and pedagogical knowledge, not a separate type of knowledge. For example, if a specialist in physics has good content knowledge in a narrow field, then the teachers of physics have to know more than physicists; they need to have superior knowledge of different aspects of physics and of numerous topics to be able to integrate different topics and provide adequate feedback to pupils (Kirschner, 2016). Studies have found that the pedagogical content knowledge of teachers has a major influence on the academic progress of pupils (Meschede et al., 2017; Reinfried et al., 2009). This raises the question of how teachers make the topic and their content knowledge understandable to their pupils (Kurt-Birel et al., 2020; Meschede et al., 2017; Ozmantar \& Akkoç, 2017; Tröbst et al., 2018).

\section{Areas and Components of Pedagogical Content Knowledge}

In order to understand the nature of pedagogical content knowledge, four yes-no questions have to be answered (Rollnick, 2017). First: Is content knowledge a component of pedagogical content knowledge or separate knowledge? The question is whether knowing the subject or the content of the area is an important prerequisite for the development of pedagogical content knowledge or whether they should be approached separately. Despite the fact that many models of subject didactics have treated content knowledge as a separate component, it is still an important aspect of subject didactics. Second: Is the pedagogical content knowledge collective or personal knowledge? The pedagogical content knowledge that is used in practice is collective and theories on which the implementation of pedagogical content knowledge is based are canonical (Rollnick, 2017). Also, pedagogical content knowledge can be specific for each teacher, as it is formed though experiences gained in real teaching situations. Third: Does pedagogical content knowledge find its expression in teachers' knowledge or actions? Kirschner (2016) believes that the pedagogical content knowledge of teachers develops hand-inhand with practice, but the transfer of knowledge to practical activities may not always take place. Fourth: Is pedagogical content knowledge domain-specific, subject-specific or topic-specific?
Some authors consider pedagogical content knowledge to be domain-specific knowledge that develops in practice and is unique to each teacher (Bohlmann, 2016; Kirschner, 2016; Rollnick, 2017). The uniqueness is expressed in the fact that teachers' pedagogical content knowledge is related to their personal values, beliefs and self-regulation (Kirschner, 2016). Other authors consider pedagogical content knowledge to be topic-specific, stressing that in order to teach any new topic, new pedagogical content knowledge must be acquired (Doyle et al., 2019; Park \& Oliver, 2008; Rollnick, 2017).

Teachers' pedagogical content knowledge starts to evolve early. Tröbst et al. (2018) have introduced a three-phase development path of pedagogical content knowledge in which beliefs about teaching start to form as early as the pupil stage when students have experiences at school. During university studies, future teachers acquire theoretical knowledge in subject didactics courses, and, develop procedural pedagogical content knowledge with the support of teaching practices and reflexion. As a result of the diversity of teachers' knowledge, components of pedagogical content knowledge are defined differently in different approaches (Rollnick, 2017, Shulman, 1987; Stender et al., 2017).

For example, in simpler approaches, two components of knowledge are distinguished: knowledge of teaching strategies and knowledge of how pupils learn and understand the subject (Deng, 2018; Meschede et al., 2017; Tröbst et al., 2018). In the case of teaching strategies, it is important that teachers know their strengths and weaknesses and are able to present the content of different subjects (e.g. giving analogies and examples, conducting experiments and observations, offering explanations and carrying out demonstrations), as well as be ready to teach in various environments. According to this classification, pedagogical content knowledge is a combination of subject-specific teaching (content and teaching) and subject-specific learning (content and pupils) (Deng, 2018; Parchmann, 2013). In addition to these components, curriculum knowledge is also considered important (Ball et al., 2008; Rosenkränzer et al., 2017; Stender et al., 2017). Linking curriculum thinking with content knowledge leads to meeting the main goal of education - to improve human capabilities (Deng, 2018) - which helps to understand the educational system as a whole (Rosenkränzer et al., 2017).

On the basis of the classification of pedagogical content knowledge proposed by Gess-Newsome (2017), various models have been developed that are used in research and modified in the teaching of subject didactics in teacher training courses. In addition to knowledge of the subject, teaching 
strategies, curriculum and learner's understandings about a subject, these models present knowledge about assessing pupils and the learning context (see Kirschner, 2016; Niermann, 2017; Reinfried et al., 2009; Stender et al., 2017). For example, for teaching natural science subjects, a model is used that highlights teaching strategies, curriculum and assessment, in addition to knowledge about the pupils, as well as the teacher's attitude towards teaching natural sciences (Deng, 2018; Richardson et al., 2018). When teaching design and technology subjects, a model is applied where different types of knowledge are linked to a teacher's specific experiences (Doyle et al., 2019). In foreign language teaching, a model of integrated pedagogical content knowledge is introduced, consisting of two specific components: the teacher's communication competence and intercultural operating competence (Eberhardt, 2013). In conclusion, different components are used in different models of subject didactics. A change in these components or an imbalance between the components leads to a change in teachers' pedagogical content knowledge (Richardson et al., 2018).

\section{The Aim and Research Questions}

The aim of the present study was to develop a theoretical model for the systematic treatment of subject didactics in primary teacher education at universities. In order to achieve that goal, the components of pedagogical content knowledge of teachers were analysed on the basis of scientific literature through a literature search and involving studies of different designs. Since the scoping literature review method is not used for seeking answers to narrow, specific questions, the quality of research was used as the main selection criterion (Dijkers, 2015). The analysis relied on the principles of drawing up an overview of literature developed by Arksey and O'Malley (2005). Three research questions were established.

1. What domains of knowledge are necessary for primary teachers to know subject didactics? 2. What components of pedagogical content knowledge are highlighted in empirical research and theoretical approaches?

3. What are the domains of knowledge that should be included in a well-functioning model of teaching subject didactics in primary teacher training?

\section{Method}

\section{Selection of Articles}

A literature search was performed through the EBSCO search engine in databases that included the Academic Search Complete, PsycARTICLES, PsycINFO and the Teacher Reference Center. The search involved bibliography entries in English and German using the following criteria to limit the search: full text, peer reviewed scientific journals and the date of publication between 2008 and 2018. The flowchart of the procedure for the selection of articles is presented in Figure 1.

\section{Figure 1}

Literature search for the selection of articles

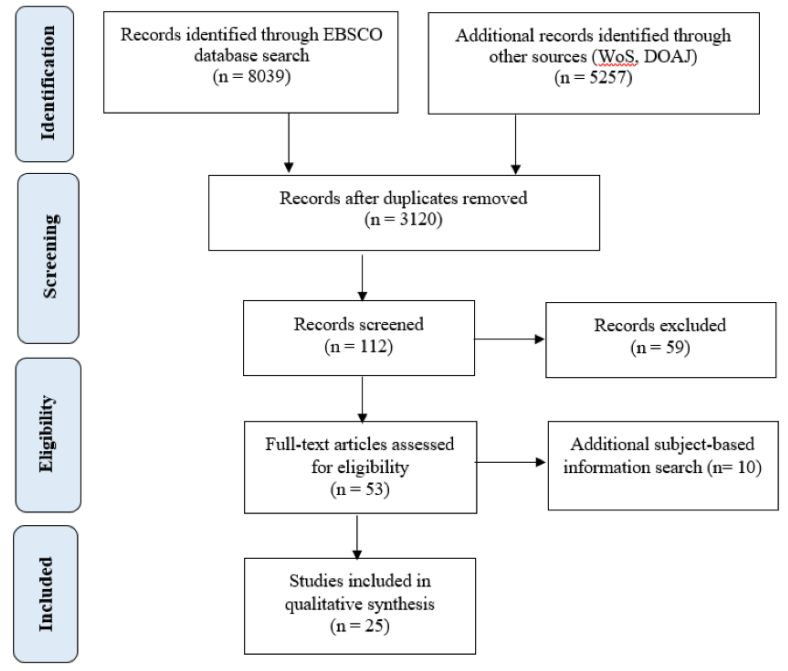

In the first phase of the search procedure, the research focused on identifying synonyms for the term 'subject didactics' and on defining the areas of topics. Several basic searches were necessary, using different keywords from the database thesaurus, e.g., 'pedagogical content knowledge', 'PCK' (acronym), 'subject-matter' and 'subject didactics' and their German equivalents: 'Fachdidaktik', 'Didaktik eines Faches', 'Fachwissen' and 'Pedagogisches Wissen'. The term 'general pedagogical knowledge' (GPK), was excluded from the search because the goal was to find articles related to teaching subject didactics. Next, the advanced search was used to define topics by combining the keywords AND and OR with the keywords that clearly indicated teacher training.

On the basis of the titles and abstracts of articles, the theories were identified where the authors had defined a base of knowledge necessary to teach subject didactics: 1) content knowledge, 2) pedagogical knowledge, and 3) pedagogical content knowledge. After reviewing the full texts of articles, those scientific articles were chosen for the qualitative synthesis that dealt with teachers' pedagogical content knowledge and its components, and whose full text was available in the database. As a result of the information search, 25 scientific articles in English and German were selected. An additional search for subject-specific scientific articles was also carried out because previously found articles were mainly about the didactics of the sciences. 


\section{Data Analysis}

As a result of literature search, 25 articles were selected. This procedure was followed by the profound assessment of the articles during which two full texts were excluded, as they did not describe the components of subject didactics. Thereafter, 23 articles that were relevant to answer three research questions were coded and analysed using qualitative inductive content analysis (Mayring, 2014; Vaismoradi, 2013). In the first phase of the analysis, the authors independently read articles to determine the domains and components of subject didactics. Next, they crosschecked articles to confirm their relevance to the research questions. In the second phase, meaningful units (phrases or sentences) were marked in the full texts and initial codes were generated. After thorough discussions with the co-authors, a coding frame was developed. The codes representing similar content were assigned to sub-categories and categories and were structured in relation to the research questions. Double-coding of the articles was conducted to ensure the trustworthiness and the quality of the study (Patton, 2002). In the third phase of the analysis, a summary was drawn up on the basis of the analysis (see Appendix). Finally, two university teachers who taught subject didactics in primary teacher training were asked to give their expert assessment of the results. These assessments have been considered in creating a theoretical model of teaching subject didactics in primary teacher education.

\section{Results and Discussion}

Based on the analysis of the scientific articles, the concept of teaching subject didactics is presented in this article, proposing a theoretical model that covers different domains and components and enables the systematisation of teaching of subject didactics in primary teacher training.

\section{Domains of Pedagogical Content Knowledge}

First, an answer was sought to the question about what are the domains of knowledge necessary for a primary teacher to know subject didactics. The analysis of articles revealed that, within the teaching of subject didactics, two interconnected groups of knowledge can be distinguished: knowledge of pedagogy and knowledge of subject didactics. This knowledge can be practical as well as theoretical (Deng, 2018) and has a multifunctional character (Heitzmann, 2013). In addition, knowledge of didactics has a close relationship with pedagogy and psychology, specialised sciences and general didactics (Heitzmann, 2013; Niermann, 2017; Reinfried et al., 2009; Vollmer, 2014) is synthesised within all subjects. At the same time, Parchmann (2013) emphasised that when subject didactics is implemented, the knowledge in different areas cannot be arithmetically combined. Pedagogical content knowledge is the 'lesson theory' (Klafki, 2000), which allows for the creation of new knowledge and integration between and across subjects.

The teacher's pedagogical knowledge has been defined by Mishra and Koehler (2006) as a general type of knowledge that includes the understanding of pupils' cognitive and social processes, learning and teaching as well as educational goals and values. Pedagogical knowledge is necessary for primary teachers to understand the psychological processes related to learning. In this connection, it is important to know how to manage teaching practices in the classroom, how to plan and organise teaching and how to assess learning outcomes. Several authors analysed in this article have dealt with pedagogical knowledge together with knowledge on methods and techniques used in the classroom (Rosenkränzer et al., 2017; Stender et al., 2017), teaching strategies (Rollnik, 2017; Rosenkränzer et al., 2017) and the particular features of pupils (Deng, 2018; Niermann, 2017). Previous studies have also shown that teachers themselves tend to value their pedagogical knowledge higher than their content knowledge, and it is difficult for inexperienced teachers to interpret classroom situations on the basis of general pedagogical principles (Meschede et al., 2017). The reason for this may be that inexperienced teachers lack pedagogic knowledge to assess situations and to find meaning in them.

Teachers' pedagogical content knowledge as a larger set of knowledge differs from general pedagogical knowledge and content knowledge by the fact that it includes multiple disciplines (Niermann, 2017; Parchmann, 2013). This type of knowledge includes the formulation and presentation of concepts (Deng, 2018; Doyle et al., 2019; Rosenkränzer et al., 2017), pedagogical techniques (Deng, 2018; Rosenkränzer et al., 2017), and knowing why the acquisition of concepts is sometimes easy for pupils and sometimes difficult (Deng, 2018; Doyle et al., 2019; Mishra \& Koehler, 2006; Rosenkränzer et al., 2017). Teachers can apply pedagogical content knowledge to deliver the content of a particular subject by choosing suitable teaching methods (Deng, 2018; Rollnik, 2017; Rosenkränzer et al., 2017). By implementing pedagogical content knowledge, teachers combine the content of the subject with general pedagogical knowledge and thereby improve the learning process (Doyle et al., 2019).

On the basis of the articles analysed in this study, three domains of knowledge were clearly distinguished in the group of pedagogical content knowledge: knowledge about the content of a subject, knowledge 
about teaching a subject and knowledge of subjectspecific assessment (see Appendix). Each of these domains included different components that are analysed and interpreted in the next chapter.

\section{Components of Pedagogical Content Knowledge}

Second, the study aimed to determine which components of pedagogical content knowledge were distinguished in empirical studies and theoretical approaches related to different domains of subject didactics. Subject didactics includes the choice of content, its legitimacy, the justification of the didactic reconstructions and teaching goals, and the methodological structuring of the learning process. As a result, the components of pedagogical content knowledge were divided into three groups.

\section{Content Knowledge}

The analysis showed that many authors paid attention to good content knowledge of a subject (Deng, 2018; Meschede et al., 2017; Parchmann, 2013) because the amount of subject knowledge supports the teacher most during the teaching of a subject (Shulman, 1986) and assessing the success of their pupils. Two components were clearly distinguished in content knowledge: the content of a subject and a teacher's knowledge about the subject (see Niermann, 2017). Knowledge about the content of a subject is domainspecific, and its importance has been highlighted in twelve articles. However, teachers' knowledge about subjects that are related to teachers' professionalism are more important than the content of subjects. Teachers' knowledge about subjects is understood as the knowledge about the substantive structure of the subjects (concepts, principles, frameworks) and the syntactical structure (methods of research, ways of presenting and certifying evidence) and the ability to transmit subjects (Porter, 2006). The articles analysed dealt much less with teachers' knowledge about subjects than the content of subjects (see Appendix Table 1). One reason may be that pedagogical content knowledge is not regarded as a different type of knowledge, but rather as a symbiosis of teachers' content and pedagogical knowledge (Bohlmann, 2016). Other authors (Heitzmann, 2013; Reinfried et al., 2009: Vollmer, 2014) highlighted the importance of subject knowledge and how to make the topics understandable to pupils and support their learning process. Thus, the broader the teachers' subject knowledge, the more they seek opportunities to transfer the subject content to their pupils (Rollnick, 2017). In passing on content, it is important to take into account the nature of the subjects and the curriculum, as well as the characteristics of the pupils of different ages and backgrounds (Deng, 2018; Meschede et al., 2017; Rosenkränzer et al., 2017).

\section{Teaching a Subject}

Three components related to teaching a subject were differentiated in the analysed articles: 1) learners' comprehension of a subject, 2) knowledge about the subject methodology and strategies, and 3) knowledge about the syllabus and curriculum, i.e. curriculum knowledge. Most of the authors (of a total of 20 articles) considered it important that teachers know how pupils learn, understand the subject and acquire knowledge (see in Appendix for Alonzo \& Kim, 2005; Deng, 2018; Krauss et al., 2008). In doing so, Deng (2018) stressed that students' previously acquired knowledge and misunderstandings condition the acquisition of subject content. If teachers know about pupils' learning difficulties, they have a better understanding of the problems encountered during the learning process (Deng, 2018; Meschede et al., 2017).

Teachers who are acquainted with effective teaching methods choose those that are most suitable, taking into account pupils' abilities, age, individual characteristics and background (Deng, 2018; Heizmann, 2013). As to teaching methods, the analysed articles mostly highlighted the methods that facilitate the acquisition of more complex concepts, such as analogy, illustrations, examples, and generalisations (Deng, 2018; Meschede et al., 2017; Rosenkränzer et al., 2017). When implementing new methodological ideas, it is important to ensure that pupils understand the content of a subject, that they are interested in it, and that they acquire knowledge effectively (Parchmann, 2013). Several studies have confirmed that teachers choose teaching methods and their content knowledge, and the quality of their qualification in subject didactics affects the quality of teaching and pupils' academic progress (see Heitzmann, 2013). Thus, experienced teachers are more precise in their explanations and teaching than are inexperienced ones (see Gess-Newsome, 2017).

Teachers' curriculum knowledge includes knowledge about a syllabus and the relevant instructional programmes (Deng, 2018). The content of a subject comes directly from a syllabus that is built on an academic discipline with social, cultural and educational objectives (Porter, 2006). However, the articles analysed exhibited an interesting trend; the authors did not emphasise the necessity of curriculum knowledge when talking about the pedagogical content knowledge of teachers. The reason may be that the curriculum is an area that requires more extensive research in order to deal with it as part of teachers' pedagogical content knowledge. At the same time, it was noted that curriculum knowledge, together with knowledge about educational objectives, differentiates teachers from a subject 
specialist (Rosenkränzer et al., 2017). For example, teachers choose the topics they teach based on what they consider to be most important, what they think pupils are ready to learn or what they like to teach (Porter, 2006).

\section{Subject-Specific Assessment}

Teachers' curriculum knowledge is closely linked to their knowledge of assessment (Stender et al., 2017). In order to understand the nature of education, it is necessary to know how to assess different aspects of a subject (Richardson et al., 2018). However, the analysed articles did not address assessment as an aspect of teachers' pedagogical content knowledge. The topic of assessment was distinguished only in six articles (e.g. Niermann, 2017; Stender et al., 2017), which may be because assessment is usually considered as a part of teachers' pedagogical knowledge. This study examines teachers' knowledge of subject-specific assessment within the context of certain subjects.

\section{The Model of Teaching Subject Didactics}

The authors of this article were interested in what pedagogical content knowledge and other types of knowledge should be included in a well-functioning model of subject didactics for primary teacher training. Having analysed the previous theoretical approaches, it appeared that researchers highlighted different components of teaching pedagogical content knowledge (Gess-Newsome, 2017; Niermann, 2017; Reinfried et al., 2010; Shulman, 1987; Stender et al., 2017). Several models describing teachers' knowledge are based on the Shulman concept (1987), which constitutes the basis for effective teaching. Shulman has identified specific knowledge, i.e. as content knowledge, pedagogical knowledge, and pedagogical content knowledge, as the knowledge necessary for teaching and assessing pupils' learning outcomes. Later studies differ from this model in terms of the number of components and their descriptions (see in Appendix for Deng 2018; Doyle et al., 2019; Parchmann, 2013; Park \& Oliver, 2008; Reinfried et al., 2009; Stender et al., 2017). However, until now, it has not been defined how to integrate teachers' content knowledge and skills, with their knowledge of assessment, pupils, curricula and characteristics of subjects and topics. These components were taken into account in this study when creating the model for teaching subject didactics to primary teachers at the university level (see Figure 2).

Based on the results of the literature search, the teachers' pedagogical content knowledge was divided into three areas. Teacher's pedagogical content knowledge can be regarded as an integrated part of pedagogical knowledge. In addition to content knowledge and the knowledge of how to teach the subject, a new area of knowledge, i.e. the knowledge about subject-specific assessment, was added to the model. Subject knowledge was added as a component of content knowledge and the teaching of a subject was broadened by adding knowledge about subject methodology. Whilst creating the model, we had to bear in mind that changing the components or the balance between the components would result in a change in teachers' pedagogical content knowledge (see Richardson et al., 2018) and their understanding of teaching

\section{Figure 2}

Model of teaching subject didactics.

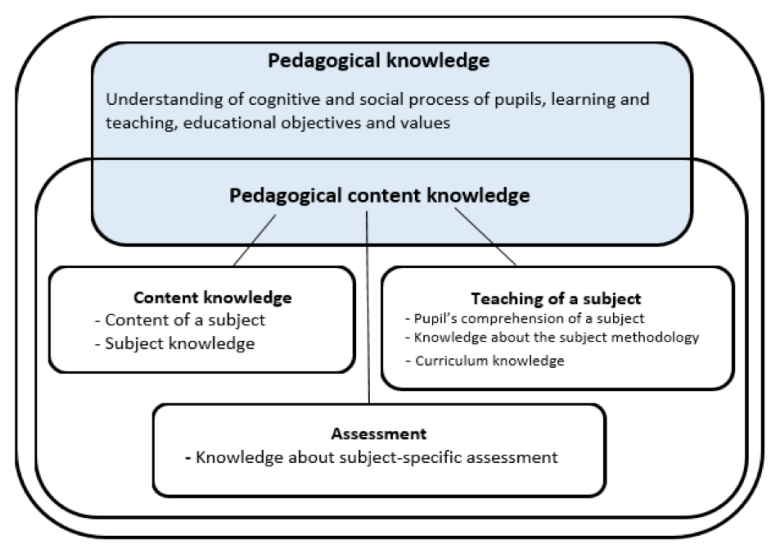

\section{Limitations and Conclusions}

This study was an attempt to organise the theoretical foundations of the teaching of subject didactics and to develop a structure for the systematic treatment of subject didactics in primary teacher training. To this end, scientific articles were analysed using the method of a scoping literature review. In doing so, some methodological limitations were encountered. First, information searches were carried out mainly through the EBSCO search engine, limiting articles to those published in the last decade. Consequently, English language articles dominated the relevant scientific articles. However, by expanding the search, the number of German language theoretical approaches can be increased.

On the basis of a theoretical model of pedagogical content knowledge, several recommendations can be made on how to organise the courses of subject didactics in primary teacher education.

1. The model is suitable for the development of disciplines teaching subject didactics, especially those that focus on preparing primary teachers. Teachers' content knowledge and knowledge of pedagogy should be treated in an integrated way. 
2. There is a discussion about the great fragmentation between different areas and disciplines related to subject didactics (Vollmer, 2014). Integrating pedagogical knowledge with subject didactics enables the shaping of primary teacher education of students to understand the teaching profession at an early stage.

3. Studying subject didactics on the theoretical and empirical levels is the driving force for developing syllabi in primary teacher education.

\section{Acknowledgement}

The study was supported by European Social Fund, project 2014-20201.02.18-0645 (Enhancement of Research and Development Capability of Teacher Education Competence Centre Pedagogicum). We would also express our gratitude to Anu Palu for her comments on the model of teaching subject didactics.

\section{References}

Arksey, H., \& O'Malley, L. (2005). Scoping studies: Towards a methodological framework. International Journal of Social Research Methodology: Theory and Practice, 8(1), 19-32.

Ball, D. L., Thames, M. H., \& Phelps, G. (2008). Content knowledge for teaching: What makes it special? Journal of Teacher Education, 59, 389-407.

Bohlmann, M. (2016). Science Education: Empirie, Kulturen und Mechanismen der Didaktik der Naturwissenschaften. Studien zum Physik- und Chemielernen, 211(10/12), 44-50.

Bonnet, A. (2009). Die Dokumentarische Methode in der Unterrichtsforschung: Ein integratives Forschungsinstrument für Strukturrekonstruktion und Kompetenzanalyse. Social Science Open Access Repository. https://www.ssoar.info/ ssoar/handle/document/33987

Deng, Z. (2018). Pedagogical content knowledge reconceived: Bringing curriculum thinking into the conversation on teachers' content knowledge. Teaching and Teacher Education, 72, 155-164.

Dijkers, M. (2015). What is a scoping review? KT Update, 4(1). http://ktdrr.org/products/update/v4n1.
Doyle, A., Seery, N., Gumaelius, L., Canty, D., \& Hartell, E. (2019). Reconceptualising PCK research in D\&T education: proposing a methodological framework to investigate enacted practice. International Journal of Technology and Design Education, 29(3), 473-491.

Eberhardt, J. (2013). Interkulturelle Kompetenzen im Fremdsprachenunterricht. Auf dem Weg zu einem Kompetenzmodell für die Bildungsstandards. Zeitschrift für Interkulturellen Fremdsprachenunterricht, 20(1). TU Darmstadt.

Gess-Newsome, J. (2017). A model of teacher professional knowledge and skill including PCK. In A. Berry, P. Friedrichsen, \& J. Loughran (Eds.), Re-examining pedagogical content knowledge in science education (pp. 28-42). Routledge.

Heitzmann, A. (2013). Entwicklung und Etablierung der Fachdidaktik in der schweizerischen Lehrerinnen- und Lehrerbildung: Überlegungen zu Rolle und Bedeutung, Analyse des IstZustands und Reflexionen für eine produktive Weiterentwicklung. Beiträge zur Lehrerinnenund Lehrerbildung, 31(1), 6-17. https://www. pedocs.de/frontdoor.php?source_opus=13830.

Kansanen, P., \& Meri, M. (1999). The didactic relation in the teaching-studying-learning process. In B. Hudson, F. Buchberger, P. Kansanen, \& H. Seel (Eds.), Didaktik/Fachdidaktik as Science(-s) of the Teaching Profession. TNTEE Publications, 2(1), 107-116.

Kirschner, S. (2016). Professionelle Kompetenz von Lehrkäften. PLUS LUCIS. https://Www.univie. ac.at/pluslucis/PlusLucis/162/S15.pdf.

Klafki, W. (2000). School quality, school program, and teacher self-evaluation. European Education, 31(4), 73-91.

Küçükaydın, M. A., \& Sağır, Ş. U. (2016). An investigation of primary school teachers' PCK towards science subjects using an inquiry-based approach. International Electronic Journal of Elementary Education, 9(1), 87-108.

Kurt-Birel, G., Deniz, Ş., \& Önel, F. (2020). Analysis of Primary School Teachers' Knowledge of Geometry. International Electronic Journal of Elementary Education, 12(4), 303-309.

Mayring, P. (2014). Qualitative content analysis: theoretical foundation, basic procedures and software solution. Klagenfurt. https://nbnresolving.org/urn:nbn:de:0168-ssoar-395173 
Meijer, P. C. (2013). Kogenud õpetaja praktiline teadmine õpetajakoolituse osana [Experienced teachers' practical knowledge as part of teacher education]. Estonian Journal of Education, 1, 8-24. http://dx.doi.org/10.12697/eha.2013.1.02.

Meschede, N., Fiebranz, A., Moller, K., \& Steffensky, M. (2017). Teachers' professional vision, pedagogical content knowledge and beliefs: On its relation and differences between preservice and in-service teachers. Teaching and Teacher Education, 66, 158-170.

Mishra, P., \& Koehler, M. J. (2006). Technological pedagogical content knowledge: A framework for teacher knowledge. Teachers College Record, 108(6), 1017-1054

Niermann, A. (2017). Professionswissen von Lehrerinnen und Lehrern des Mathematikund Sachunterrichts. https://www.pedocs.de/ frontdoor.php?source_opus=12587.

Ozmantar, M. F., \& Akkoç, H. (2017). Voices and values in shaping the subjectivity of pedagogical content knowledge. Cogent Education, 4, 1401195. https://doi.org/10.1080/2331186X.2017.1401195.

Parchmann, I. (2013). Wissenschaft Fachdidaktik Eine besondere Herausforderung. Beiträge zur Lehrerinnen- und Lehrerbildung, 31(1), 31-41. https://core.ac.uk/download/pdf/83643118.pdf.

Park, S., \& Oliver, J. S. (2008). Revisiting the conceptualisation of pedagogical content knowledge (PCK): PCK as a conceptual tool to understand teachers as professionals. Research in Science Education, 38(3), 261-284.

Patton, M. Q. (2002). Two Decades of Developments in Qualitative Inquiry: A Personal, Experiential Perspective. Qualitative Social Work, 1(3), 261283.

Porter, A. (2006). Curriculum assessment. In J. L. Green, G. Camilli, \& E. L. Elmore (Eds.), Handbook of complementary methods in education research (pp. 141-159). American Educational Research Association.

Reinfried, S., Mathis, C., \& Kattmann, U. (2009). Das Modell der Didaktischen Rekonstruktion. Eine innovative Methode zur fachdidaktischen Erforschung und Entwicklung von Unterricht. Beiträge zur Lehrerinnen- und Lehrerbildung, $27(3), 404-414$.
Richardson, G. M., Byrne, L. L., \& Liang, L. L. (2018). Making learning visible: Developing preservice teachers' pedagogical content knowledge and teaching efficacy beliefs in environmental education. Applied Environmental Education \& Communication, 17(1), 41-56.

Rollnick, M. (2017). Learning about semi - conductors for teaching - the role played by content knowledge in pedagogical content knowledge (PCK) development. Research in Science Education, 47, 833-868. doi: 10.1007/s11165-0169530-1.

Rosenkränzer, F., Hörsch, C., Schuler, S., \& Riess, W. (2017). Student teachers' pedagogical content knowledge for teaching systems thinking: Effects of different interventions. International Journal of Science Education, 39(14), 1932-1951.

Shulman, L. (1986). Those who understand: Knowledge growth in teaching. Educational Researcher, 15(2), 4-14. doi: https://doi. org/10.3102/0013189×015002004.

Shulman, L. (1987). Knowledge and teaching: Foundations of the new reform. Harvard Educational Review, 57, 1-23.

Stender, A., Brückmann, M., \& Neumann, K. (2017). Transformation of topic-specific professional knowledge into personal pedagogical content knowledge through lesson planning. International Journal of Science Education, 39(12), 1690-1714.

Studies in Social and Educational Sciences from 2008 to 2013. From Theory into Practice. (2014). [Sotsiaalja kasvatusteaduste valdkonna uuringud 2008-2013. Teooriast praktikasse.] (2014). Eesti Teadusagentuur. https://www.etag.ee/wpcontent/uploads/2014/04/kasvatusuuringud. pdf.

Tröbst, S., Kleickmann, T., Heinze, A., Bernholt, A., Rink, R., \& Kunter, M. (2018). Teacher knowledge experiment: Testing mechanisms underlying the formation of preservice elementary school teachers' pedagogical content knowledge concerning fractions and fractional arithmetic. Journal of Educational Psychology, 110(8), 10491065.

Unt, I. (2013). Didaktika. [Didactics]. In Mikser, R. (Ed.), Haridusleksikon. Eesti Keele Sihtasutus. 
Vaismoradi, M., Turunen, H., \& Bondas, T. (2013). Content analysis and thematic analysis: Implications for conducting a qualitative descriptive study. Nursing \& Health Sciences, 15(3), 398-405.

Vollmer, (2014). Fachdidaktik and the development of generalised subject didactics in Germany. https://journals.openedition.org/ educationdidactique/1861?lang=en. 


\section{Appendix}

Domains and components of subject didactics in the literature search

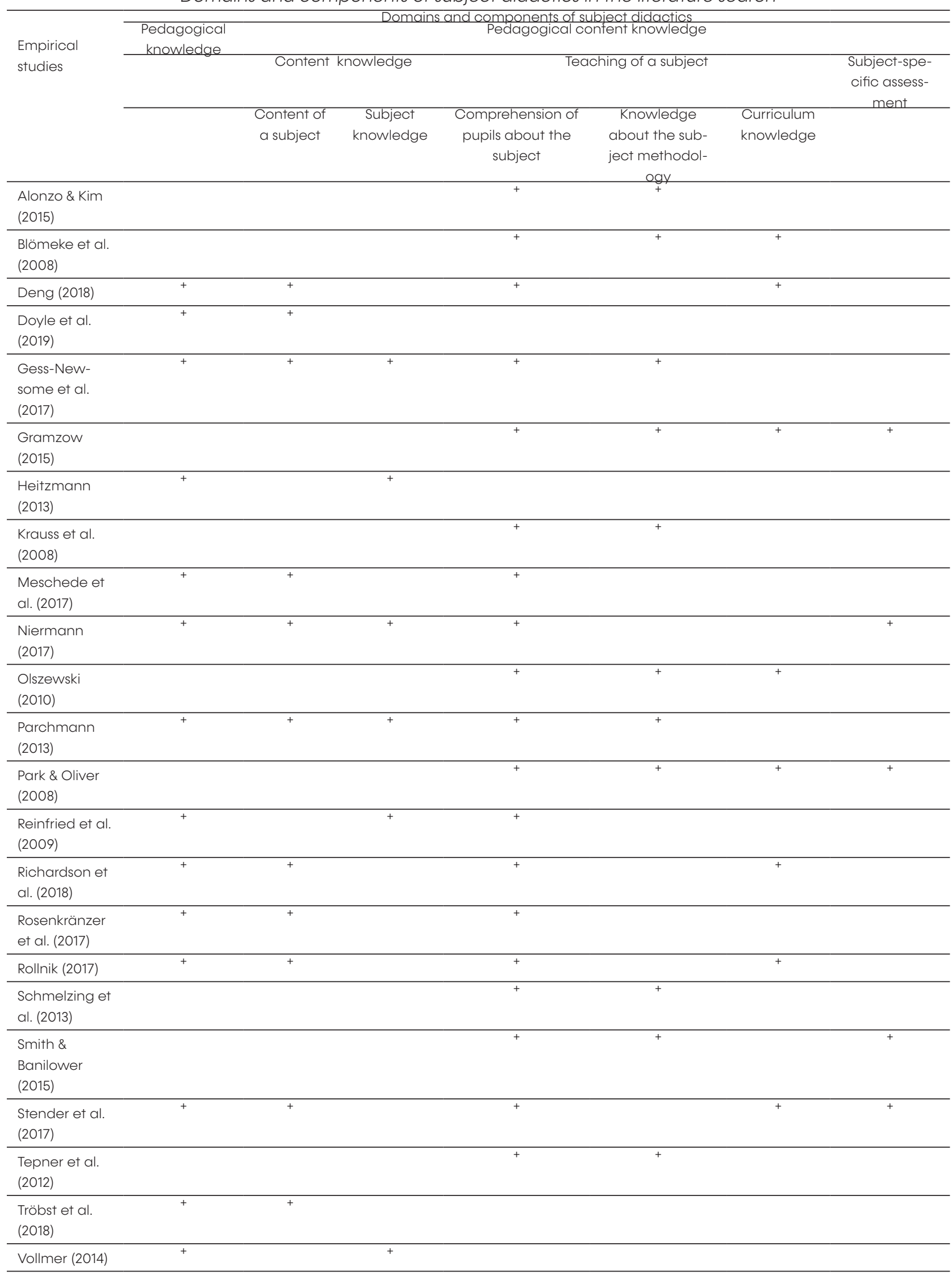

